\title{
Ultra-high sensitivity measurement of DNA sequences with conducting polymer-modified electrodes: mechanism, large-scale manufacture, and prospects for rapid polymerase chain reaction measurement (e-PCR)
}

\author{
Bicheng Zhuª,b, Thomas Kerr-Philips ${ }^{\mathrm{a}}$, Zahraa Al Ghaus ${ }^{\mathrm{a}}$, Eddie Wai Chi Chan ${ }^{\mathrm{a}, \mathrm{b}}$, David \\ Barker $^{\mathrm{a}, \mathrm{b}}$, Clive W. Evans ${ }^{\mathrm{a}, \mathrm{c}}$, David E. Williams, ${ }^{* a, b}$ Jadranka Travas-Sejdic* a,b
}

\begin{abstract}
:
At low copy number, sequence detection by polymerase chain reaction (PCR) requires up to 30 cycles (amplification by a factor of $10^{9}$ ) to produce a reliably detectable concentration of fluorescently-labelled amplicons. The cycle number and hence detection time is determined by the analytical sensitivity of the detector. Hybridisation of complementary DNA strands to oligonucleotide-modified conducting polymer electrodes yields an increase in the charge transfer resistance for the ferri-ferrocyanide redox couple. Sensors using this technology for e-PCR offer a label-free method with detector sensitivity in the pM range, potentially decreasing the required cycle number from 30 to 10 and offering a much simplified instrument construction. We demonstrate sensors using screen-printed carbon electrodes modified with a conducting polymer formed from a monomer pre-functionalised with complementary oligonucleotide. Off-chip pre-functionalisation of the conducting polymer precursor is a key step towards practical manufacture and the method is potentially a general one for sensors which require a capture probe-functionalised surface. We demonstrate reliable sensitivity of the interfacial resistance change at the pM scale for short (20-mer) sequences and at the aM scale for bacterial lysate, with dynamic range extending to $\mu \mathrm{M}$ scale and response time-scale $5 \mathrm{~min}$. Donnan exclusion of the redox couple from the surface, as previously proposed, seems unlikely as a mechanism for such ultra-high sensitivity. We demonstrate that the most important element in the response at the lowest concentrations is due to variation of an electrical resistance within the polymer film. We develop a mechanism based on repulsion from the solution interface of dopant anions and attraction towards and trapping at the interface of radical cations (polarons) by the charge associated with surface-bound DNA. With results for $>160$ single-use sensors, we formulate a response model based on percolation within a random resistor network and highlight challenges for large-scale manufacture of such sensors. We propose a PCR device concept for rapid use at point-of-sampling.
\end{abstract}

Key words: polymerase chain reaction, PCR, conducting polymer, screen printed carbon electrode, DNA detection, percolation conductivity, sensor manufacture

There is an urgent need to simplify and speed up DNA detection in clinical and environmental samples: the combination of polymerase chain reaction (PCR) with an electrochemical detection method is an attractive option for doing this since it offers a combination of a robust

\footnotetext{
a. Polymer Biointerface Centre, School of Chemical Sciences, The University of Auckland, 23 Symonds Street, Auckland 1010, New Zealand

b. MacDiarmid Institute for Advanced Materials and Nanotechnology, Victoria University of Wellington, Laby Building Kelburn Campus Victoria University of Wellington, Wellington 6012, New Zealand

c. School of Biological Sciences, The University of Auckland, 24 Symonds Street, Auckland 1010, New Zealand
} 
and specific amplification method with a simplified and sensitive detection instrument. Electrochemical methods for DNA sensing are indeed of great general interest, because of the simplicity, sensitivity and low cost of the measurement. Similarly, conducting polymers have been widely investigated as both sensing signal transducing substrates and as an anchor for biomolecular probes ${ }^{1-5}$, for the optical or electrochemical detection of oligonucleotides (ONs) 6-11, proteins ${ }^{12-14}$ and small molecular targets of biological interest, such as hormones ${ }^{15-16}$. In terms of miniaturization and fabrication of portable sensing devices, electrochemical impedance spectroscopy (EIS) is often employed as a readout methodology, as it can detect minor changes in the properties of the electrode surface, including those induced by biorecognition events. EIS has been widely used for the detection of biomolecules ${ }^{1}$, including DNA ${ }^{6,8}$, , proteins ${ }^{17}$ and whole cells ${ }^{18}$. Specifically, for DNA measurement, gold electrodes modified with self-assembled monolayers of thiolated oligonucleotides have been extensively studied ${ }^{19-22}$. Issues of stability of such electrodes have been well- documented ${ }^{23}$. The use of CPs with oligonucleotide covalently bound avoids at least some of these issues and in conjunction with EIS can detect ON hybridization with high sensitivity ${ }^{4,24}$. The signal can be manipulated by altering the length ${ }^{25}$, charge ${ }^{26}$ and surface packing density of the capture probe ${ }^{27}$. Different mechanisms appear to operate over different concentration ranges: Donnan exclusion of the redox couple from the nanoporous interface ${ }^{7}$ (the same mechanism as proposed for thiolated oligonucleotide-modified gold electrodes ${ }^{19,28}$ ) and modulation of charge trapping in the polymer at the polymer-solution interface ${ }^{7,29}$, exploiting a nanowire in a configuration analogous to a liquid-gated field effect transistor. We developed this work into an electrochemical PCR method (e-PCR) that exploited the high sensitivity offered to yield results significantly faster than could be obtained with conventional fluorescence detectors ${ }^{30}$. More recently, we have developed a procedure for pre-attachment of ON probes onto CP monomers, thus opening the possibility of large-scale production of probe-functionalised sensors by simply applying a short potential pulse onto the electrode immersed in the monomer-ON solution. We demonstrated sensitive detection of short Non-Hodgkin lymphoma- and chronic lymphocytic leukemia-specific DNA sequences using either researchgrade glassy carbon electrodes, gold electrodes or electrospun conductive mesh electrodes that had been surface-modified in this way ${ }^{6,8}$

Sensitive and specific detection of bacterial contamination in food and water is a compelling target for sensor development. Farabullini et al. reported a disposable electrochemical gene sensor for the simultaneous analysis of different food-contaminating pathogenic bacteria by using thiol-labelled oligonucleotide probes immobilised on a screen-printed array with four gold electrodes ${ }^{31}$. Their sensor showed a negligible sensing response to $E$. coli genomic DNA by utilizing a Salmonella 12-mer oligonucleotide probe. Liao et al. reported an electrochemical sensor assay involving hybridization of DNA in E. coli bacterial lysates to both fluoresceinmodified detector probes and biotin-modified capture probes anchored to a sensor surface. The length of capture probe in the electrode surface was a 35-mer ${ }^{32}$. The challenge, however, is the development of practical single-use, batch-calibrated devices of the required sensitivity and specificity that are mass-manufacturable. The development of portable and disposable biosensors and chemical sensors has largely utilised screen-printed electrodes (SPEs) ${ }^{33-37}$. Among SPEs, screen-printed carbon electrodes (SPCEs) are the most commonly used as they are inexpensive, suitable for industrial-scale manufacturing and have a wide potential window for electrochemical measurements ${ }^{38}$. There is a clear incentive to extend the studies of DNA 
measurement with conducting polymer-modified electrodes to SPEs, exploiting the idea of using pre-attachment of $\mathrm{ON}$ probes onto $\mathrm{CP}$ monomers, in order to explore the possible translation of this sensing technology, based on readily-fabricated, disposable sensing strips, into a commercial, portable and cost-effective device, particularly in its application as a detector for amplicons in PCR. However, there is a gap to fill in the understanding of the mechanism of response, particularly relating to the high sensitivity in conjunction with a wide dynamic range. The present work addresses that gap in understanding. Measurement of the response of a large number of disposable, CP-modified SPCEs and modelling the behavior as that of a random resistor network highlights challenges in repeatability of manufacture. We use a quartz-crystal microbalance to provide independent confirmation that DNA does indeed hybridise to the surface-conjugated probe. 
A

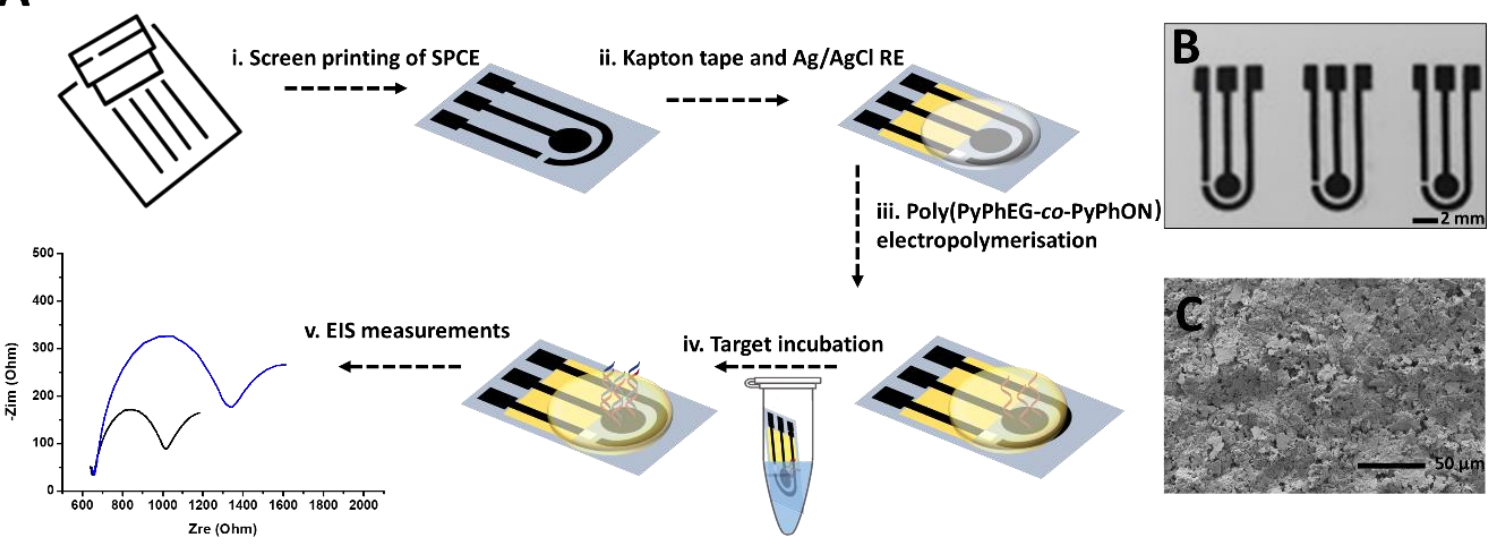

Scheme 1. (A) Scheme outlining the sensor fabrication process and target DNA detection: (i) screen printing of SPCEs; (ii) covering the electrode tracks by Kapton tape and 'painting' of $\mathrm{Ag} / \mathrm{AgCl}$ paste that serves as a reference electrode; (iii) electropolymerisation of poly(PyPhEGco-PyPhON) onto the SPCE in a $20 \mu \mathrm{L}$ droplet of co-monomer solution deposited on the electrode ; (iv) incubation of the CP-modified SPCE in $100 \mu \mathrm{L}$ of the target solution in a $1.5 \mathrm{~mL}$ Eppendorf tube, and $(\mathrm{V})$ measuring EIS before and after incubation of the electrode in the target solution; EIS was performed in a $20 \mu \mathrm{L}$ drop of $10 \mathrm{mM} \mathrm{K}{ }_{3}\left[\mathrm{Fe}(\mathrm{CN})_{6}\right] / \mathrm{K}_{4}\left[\mathrm{Fe}(\mathrm{CN})_{6}\right]$. (B) Optical photograph of SPCEs; and (C) SEM image of a bare SPCE surface, showing the rough morphology of SPCE.

\section{Results and discussion}

\section{(a) QCM-D confirmation of specific hybridization to the pre-functionalised electropolymerised film}

The method for attachment of a capture probe to a sensor surface employed here is very different from that usually practiced, in which a sensor surface is first prepared and then a capture probe is conjugated. Here, the functionalization is done "off-chip", before polymerization, thus very significantly simplifying the route to mass manufacture. Therefore, confirmation (independently of electrochemical measurement) that the ON-functionalised electropolymerised film indeed specifically binds the target, was sought using QCM-D. The frequency precision of $0.01 \mathrm{~Hz}$ corresponds to a mass change of $0.025 \mathrm{ng} / \mathrm{cm}^{2}$, in turn corresponding to $4.8 \times 10^{-13} \mathrm{~mol} / \mathrm{cm}^{2}$ of $\mathrm{ON}$ (or, if all in solution, to $30 \mathrm{nM}$ ). This frequency precision dictated the concentration range to be explored which, though comparable to many literature reports, is significantly greater than the detection sensitivity of the electrochemical method reported below. Figure $1(\mathrm{~A})$ shows the frequency change after flowing $10 \mu \mathrm{M}$ and 50 $\mu \mathrm{M}$ C-ON or Nc-ON solutions over the poly(PyPhEG-Co-PyPhON) modified crystal in the QCM$D$ flow cell. The introduction of $\mathrm{C}-\mathrm{ON}$ solutions resulted in a decrease in the quartz crystal frequency, corresponding to an increase in the mass on the crystal surface (Figure $1(C)$ ). To remove any non-specifically bound C-ON, HPB was subsequently introduced into the QCM-D chamber. The final mass change was 0.62 and $2.11 \mathrm{ng} / \mathrm{cm}^{2}$ for $10 \mu \mathrm{M} \mathrm{C}-\mathrm{ON}$ and $50 \mu \mathrm{M}$ C-ON solutions after considering the hydration of ss-ON and ds-ON ${ }^{39}$, corresponding to $1.7 \times 10^{13} \mathrm{C}$ - 
$\mathrm{ON} / \mathrm{cm}^{2}$ and $5.6 \times 10^{13} \mathrm{C}-\mathrm{ON} / \mathrm{cm}^{2}$, respectively. Figure 1 (C) gives a comparison of the mass change in response to $\mathrm{C}-\mathrm{ON}$ and $\mathrm{Nc}-\mathrm{ON}$ solutions passed through the flow cell. The resulting mass change was two- and six-times larger for $10 \mu \mathrm{M}$ and $50 \mu \mathrm{M}$ C-ON target solutions, respectively, compared to that for Nc-ON. These results confirm that the majority of the signal comes from specific DNA hybridization, while some residual non-specific adsorption of ONs occurs.

The changes in dissipation values $\left(0.02 \times 10^{-6}\right.$ and $\left.0.027 \times 10^{-6}\right)$ after introducing $10 \mu \mathrm{M}$ and 50 $\mu \mathrm{M}$ C-ON solutions, respectively (Figure $1(\mathrm{~B})$ ), mirror the quartz crystal frequency changes. The changes in dissipation after exposing the film to the solution of $\mathrm{C}-\mathrm{ON}$ reflect the formation of a more rigid layer of dsDNA, upon hybridization of the C-ON to the surface-bound ON probe 40-41.
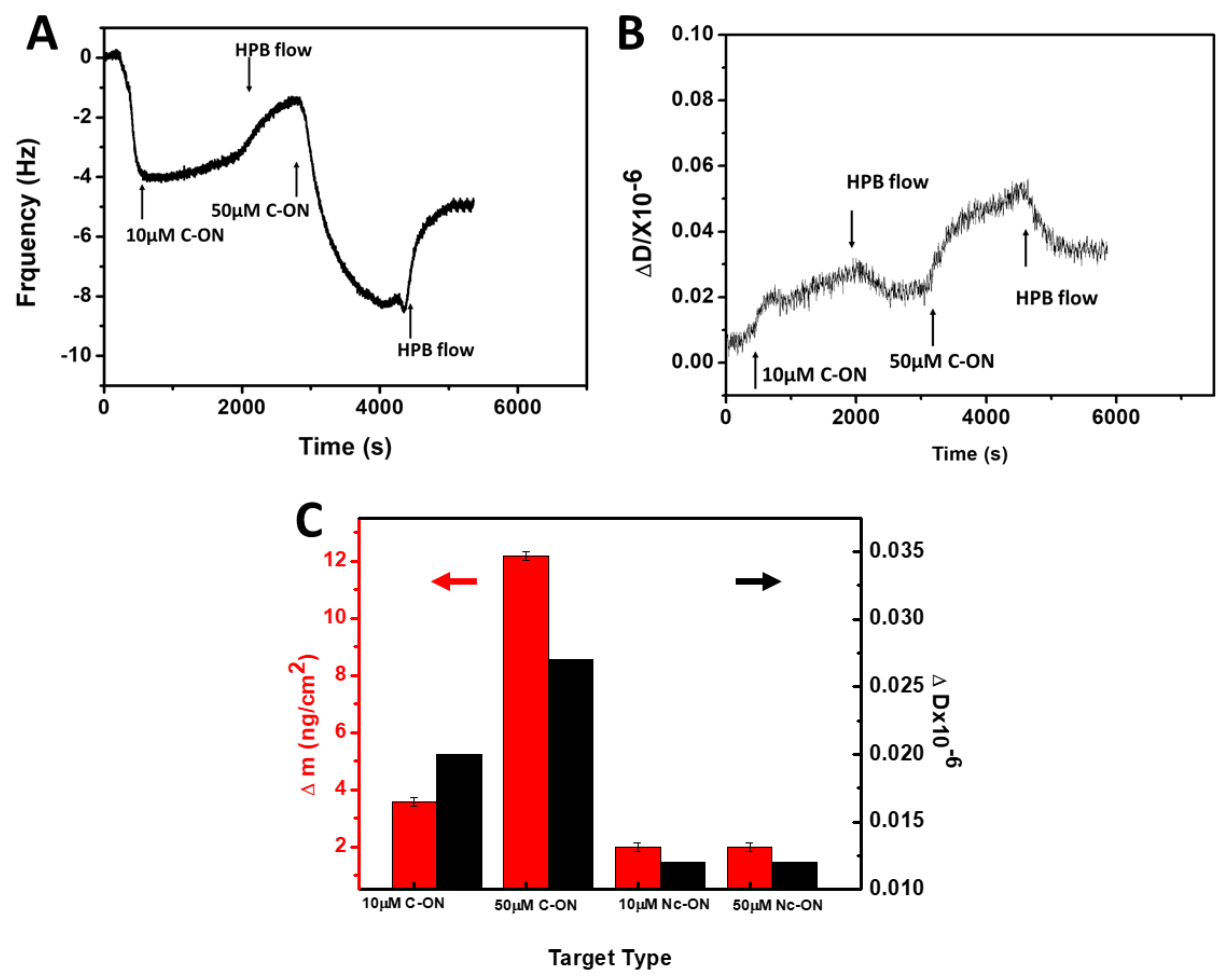

Figure 1. (A) The change in QCM frequency of poly(PyPhEG-co-PyPhON) (10:1)-modified goldcoated QCM quartz surface upon introducing $10 \mu \mathrm{M}$ and $50 \mu \mathrm{M} \mathrm{C-ON}$ target into the detection chamber. (B) Dissipation shifts (the data were smoothed using the Savitzky-Golay method). (C) Comparison in mass change (red) and dissipation shift (black) from complementary (C-ON) and non-complementary (Nc-ON) solutions $(n=3)$.

(b) Impedance response of the poly(PyPhEG-co-PyPhON) modified SPCE DNA sensor to synthetic single-stranded ON targets

The Nyquist diagram for the unmodified SPCE in the presence of the redox couple showed a simple Randles equivalent circuit with a charge transfer resistance that was significantly variable from one electrode to another, in the range 5000-7000 $\Omega$ (Figure S3). Polymer 
modification changed the equivalent circuit to that generally used to describe the electrochemical impedance of a semiconductor-redox electrode involving charge transfer through surface states ${ }^{42}$. Figure 2 shows titration series on single electrodes, for both complementary and non-complementary $\mathrm{ON}$, with impedance fitted to this equivalent circuit.

A

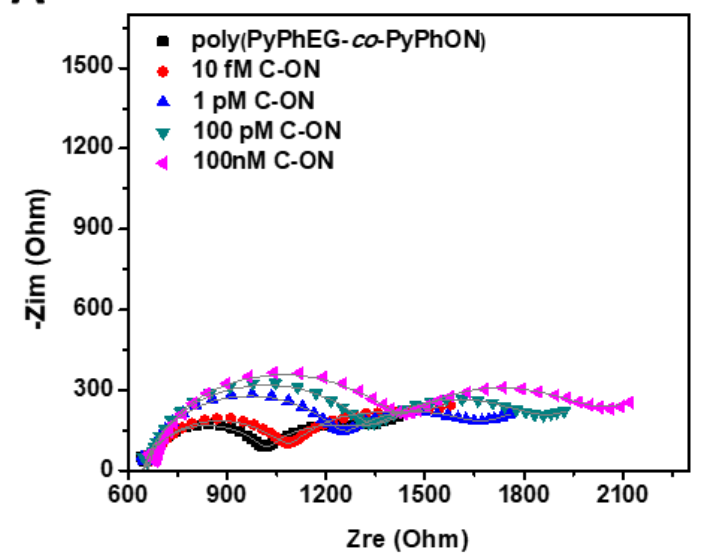

B

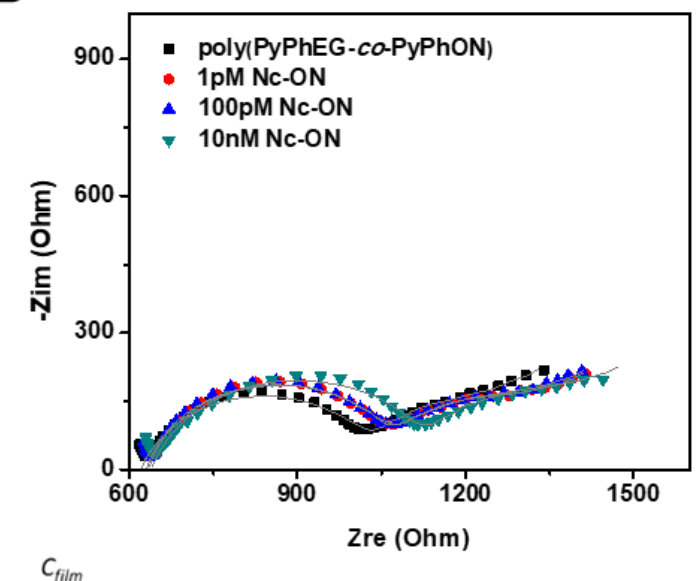

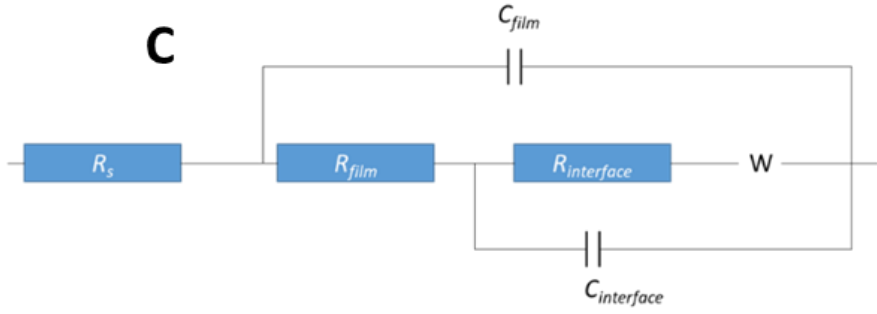

Figure 2. Impedance response to increasing concentration of oligonucleotide. A): complementary; B): non-complementary. C): equivalent circuit. Lines are the fit, points are the experimental data. Fitting was done with constant phase elements, which showed that both could be represented as simple capacitors for the purpose of interpretation (power, $\alpha$, $=0.95-1$ for $C_{\text {film }}$ and $0.85-0.92$ for $C_{\text {interface }}$. The geometric capacitance of the electrode assembly, in parallel with the entire circuit and giving rise to the additional feature at the highest frequency, is not fitted.

In this circuit model, the elements are assigned to the resistance along the electrode connector tracks, $R_{s}$, the resistance of the polymer film, $R_{\text {film }}$, the charge transfer resistance between the redox couple (diffusion impedance, $\mathrm{W}$ ) and interface states, $R_{\text {interface, }}$ a geometric capacitance due to the film, $C_{\text {film }}$, and a capacitance associated with the interface states, $C_{\text {interface. }}$ Both $R_{\text {film }}$ and $1 / C_{\text {film }}$ varied linearly with increase of polymerization time (Figure S4) consistent with the expected linear increase of film thickness with polymerization time following an initial nucleation and spreading phase; $R_{\text {interface }}$ and $C_{\text {interface }}$ varied less markedly (Table S1) also as expected. The slight depression of the low-frequency semicircle in the Nyquist plots, due to the parallel combination of $R_{\text {interface }}$ and $C_{\text {interface }}$, is consistent with the effect of roughness of the conducting polymer surface, which may increase with increasing polymerization time. The effect of the complementary ON was marked, being observable in this particular series starting at $10 \mathrm{fM}$ concentration. The effect of non-complementary ON was much smaller. 
Figure 3 shows the variation of circuit element values with $\mathrm{ON}$ concentration, derived from the data of Figure 2 . The resistances $R_{\text {film }}$ and $R_{\text {interface }}$ varied logarithmically with concentration, giving both a high sensitivity and a wide dynamic range. The response extended to the concentration range probed above by QCM-D. The element ascribed to the resistance of the polymer film varied more strongly and indeed contributed the major part of the response. The film capacitance was constant and consistent with that expected for a thin organic layer. The capacitance $C_{\text {interface }}$ was, as expected, much higher: in the range $30-100 \mu \mathrm{F}$ for different electrodes but not detectably dependent on ON concentration.

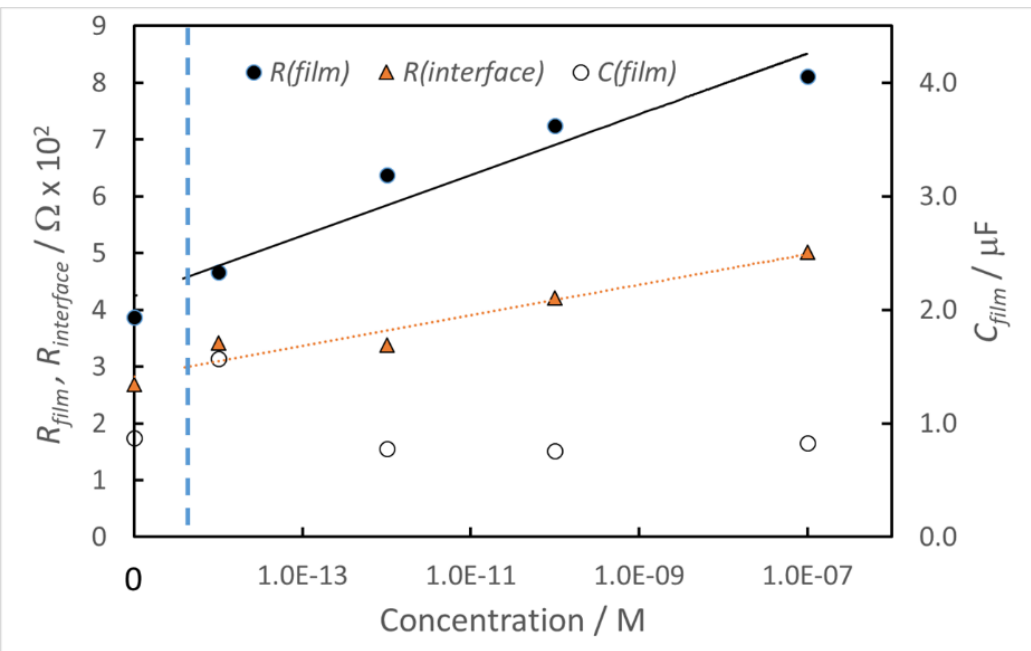

Figure 3. Variation of equivalent circuit element values with concentration of complementary $\mathrm{ON}$, for a single electrode measured in a titration series.

The value of $R_{\text {film }}$ for different electrodes was significantly variable. Figure 4 shows that the distribution of values was log-normal, broadening and shifting with increasing concentration of complementary ON. The resistance change in response to the presence of complementary ON was approximately linearly related to the 'zero' resistance (in the absence of ON) though with significant scatter.
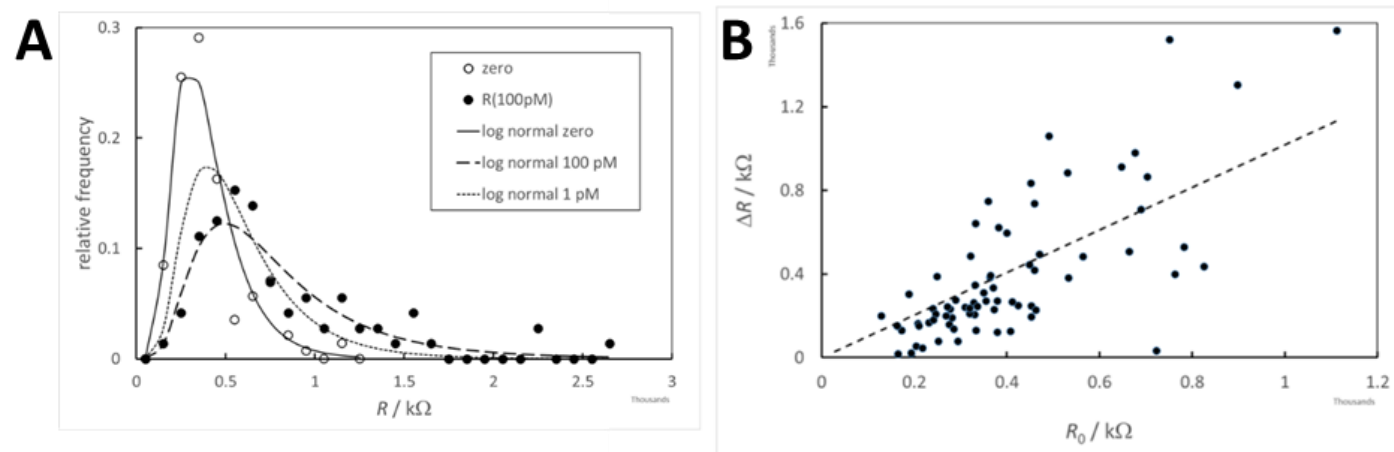
Figure 4. Distribution of film resistance measured for a large number of electrodes, and the change with increasing concentration of ON. A): Film resistance distribution fitted to lognormal (data points and fit shown for zero and 100 pM; fit only shown, for clarity, for $1 \mathrm{pM}$ ); B) Film resistance change caused by addition of $100 \mathrm{pM}$ complementary $\mathrm{ON}$ : $\Delta R_{\text {film }}$ against film resistance in the absence of complementary ON $\left(R_{f i l m}, 0\right)$. Each point is the result for a different electrode.

In view of the linear dependence of $\Delta R_{\text {film }}$ on $R_{f i l m, o}$, the ratio $\Delta R_{\text {film }} / R_{\text {film }, o}$ was taken as the sensor response, and in view of the variability the question asked: what concentration could reliably be distinguished by a single-use sensor from the non-specific signal due to noncomplementary ON? In Figure 5, results from a large number of single-use sensors are presented as violin and box-and-whisker plots. In Table 2, for the different datasets the probability that mean (t-test) and variance (F-test) are the same, assuming normal distributions, and probability that the distributions are the same using the non-parametric Kolmogorov-Smirnov (K-S) and Mann-Whitney (M-W) tests, is presented. Here, 'blank' refers to the case where the test solution contained no ON, and thus tests for signal change caused by drift of unknown origin resulting from the manipulation of the device. Figure 5 also shows the effect of varying PyPhEG:PyPhON (ratio of diluent to probe on the surface) (Figure 5(B)), the polymerization time (Figure 5(C)) and incubation time (Figure 5(D)).
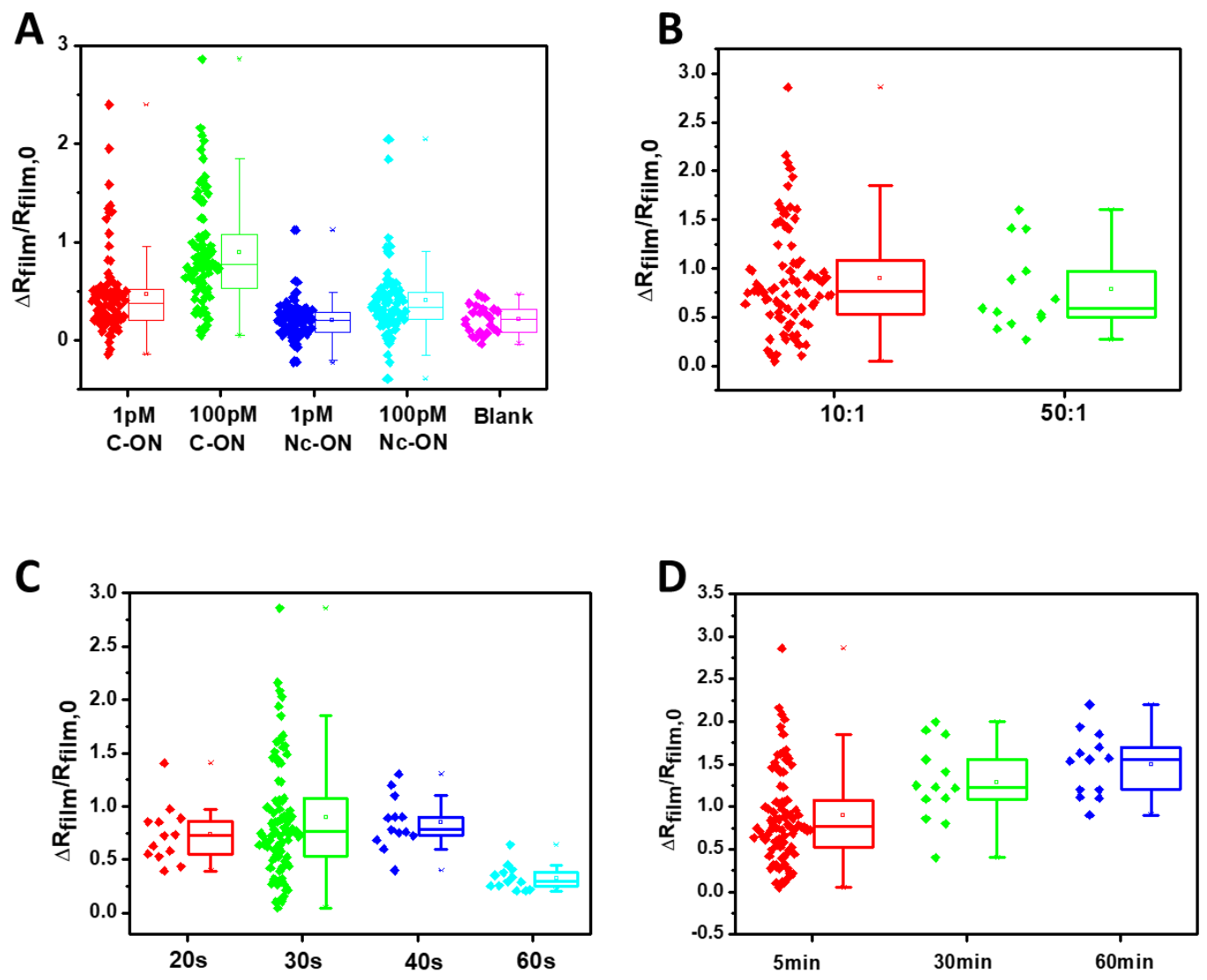
Figure 5. (A) Normalised responses of the poly(PyPhEG-co-PyPhON) (10:1) modified SPCE sensors, $\triangle R_{\text {film }} / R_{\text {film, }, 0}$; box-and-whiskers plots show the data points, mean, median and upper and lower quartiles for each condition, where each measurement is on a fresh electrode ( $\mathrm{n}=85$ for $\mathrm{C}-\mathrm{ON}, 81$ for Nc-ON and 24 for blank). Incubation time was $5 \mathrm{~min}$ and probe density 10:1 PyPhEG:PyPhON in the polymerisation solution. (B) Effect of the probe density on the poly(PyPhEG-co-PyPhON) sensor signal, $\Delta R_{\text {film }} / R_{\text {film, }, 0}$, after incubation with 100 pM C-ON, with molar ratios of PyPhEG:PyPhON in the polymerization solution 10:1 or 50:1 ( $n=85$ for 10:1, and $\mathrm{n}=12$ for $50: 1$ ). (C) Changes in sensor signal $\Delta R_{\text {film }} / R_{\text {film }, 0}$ as a function of polymerization time after incubation with $100 \mathrm{pM} \mathrm{C-ON} \mathrm{(} \mathrm{n}=85$ for 30s, and $\mathrm{n}=12$ for 20s, 40s and 60s). (D) $\triangle R_{\mathrm{ct}} / R_{\mathrm{ct}}{ }^{0}$ of poly(PyPhEG-co-PyPhON) (10:1) after incubation with $100 \mathrm{pM}$ C-ON vs. detection time.

Table 2. Statistical data for the sensing signals detecting synthetic ONs. For the datasets compared, probability that mean (t-test) and variance (F-test) are the same, assuming normal distributions, and probability that the distributions are the same using the non-parametric Kolmogorov-Smirnov (K-S) and Mann-Whitney (M-W) tests.

\begin{tabular}{ccccccc}
\hline & $\begin{array}{c}\text { 1 pM C- } \\
\text { ON and } \\
\text { Blank }\end{array}$ & $\begin{array}{c}100 \text { pM } \\
\text { C-ON } \\
\text { and } \\
\text { Blank }\end{array}$ & $\begin{array}{c}\text { 1 pM Nc- } \\
\text { ON and } \\
\text { Blank }\end{array}$ & $\begin{array}{c}1 \text { pM C-ON } \\
\text { and 100 pM } \\
\text { C-ON }\end{array}$ & $\begin{array}{c}1 \text { pM C-ON } \\
\text { and 1 pM Nc- } \\
\text { ON }\end{array}$ & $\begin{array}{c}100 \text { pM C-ON } \\
\text { and 100 pM } \\
\text { Nc-ON }\end{array}$ \\
\hline t- test & 0.005 & $<0.001$ & 0.9 & $<0.001$ & $<0.001$ & $<0.001$ \\
F-test & $>0.99$ & $>0.99$ & 0.9 & 0.97 & $>0.99$ & 0.99 \\
K-S test & 0.005 & $<0.001$ & 0.9 & $<0.001$ & $<0.001$ & $<0.001$ \\
M-W test & $<0.001$ & $<0.001$ & 0.6 & $<0.001$ & $<0.001$ & $<0.001$ \\
\hline
\end{tabular}

Although there is a significant scatter in the results, the analysis confirms: (1) the results for $1 \mathrm{pM} \mathrm{Nc-ON}$ and blank are the same; (2) a significant signal over both the blank and $1 \mathrm{pM}$ NcON for complementary $\mathrm{ON}$ at concentration of $1 \mathrm{pM}$ and a significant increase of signal with increasing concentration of complementary ON; (2) significant specificity for complementary over non-complementary $\mathrm{ON}$ at the same concentration; (3) although the variance of the different distributions is essentially the same, there is broadening of the signal distribution over that for the blank, that increases with increasing concentration for the complementary $\mathrm{ON}$ and that is also observable for the non-complementary $\mathrm{ON}$ at $100 \mathrm{pM}$.

The probe density did not have a significant effect over the range investigated. The polymerisation time (translating into the thickness of the polymer) was marginally optimal at $30 \mathrm{~s}$, where the distribution of signal values was also broadest; at the longest polymerization time explored, the mean signal was significantly diminished and the distribution of signal values significantly narrowed. The average thickness of the polymer film for $30 \mathrm{sec}$ of polymerisation time was estimated to be $20 \pm 5 \mathrm{~nm}^{43}$.

A short detection time is considered a key parameter in developing disposable and portable DNA sensors for field use, where the time from sampling to results is critical. The incubation 
time was investigated by incubating the sensor with 100 pM C-ON solution (Figure 5 (D)). The sensor response, $\Delta R_{\text {film }} / R_{\text {film }, 0}$, after 5 min incubation time reached ca. $70 \%$ of the maximum signal (taken as after $60 \mathrm{~min}$ ), and provided sufficient compromise between the signal intensity and time of analysis.

\section{(c) Sensor response to bacterial lysate}

The sensor response to bacterial lysate fitted well to the equivalent circuit of Figure 2(C). Data and fitted curves are given in the Figure S5, Table S2 and S3. Figure 6 shows the variation in the fitted parameters for titration series on single electrodes, for the specific target $E$. coli BL21 and for the control Salmonella. There is a clear specific signal in the film resistance, $R_{\text {film }}$, with a detectable difference from the measurement in buffer at $5 \times 10^{3} \mathrm{CFU} / \mathrm{mL}$. With increase of lysate concentration, the film capacitance also shows a decrease in response to the specific target. The response shown to Salmonella is much smaller. Figure $6(C)$ compares the distribution of response on multiple single-use electrodes expressed as $\Delta R_{\text {film }} / R_{\text {film }}{ }^{0}$ at different concentrations of the bacteria. The statistical evaluation is given in Table 3.
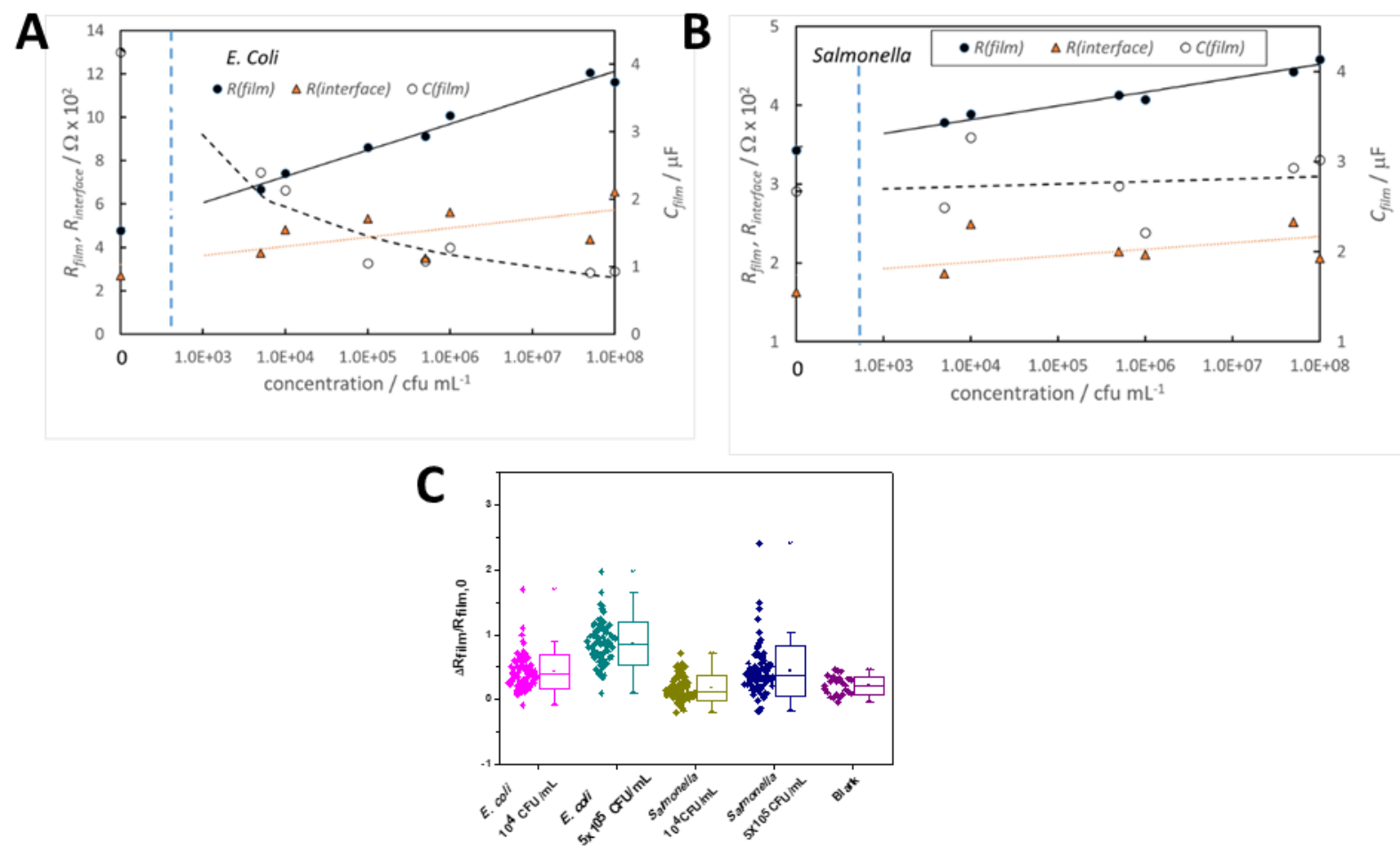

Figure 6. Representative Nyquist plots of poly(PyPhEG-co-PyPhON) (10:1) modified SPCE before and after detection of different concentrations of (A) E. coli and (B) Salmonella Lysate (solid line); (C) $\triangle R_{\text {film }} / R_{\text {film, } 0}$; box-and-whiskers plots show the data points, mean, median and upper and lower quartiles for each condition of the poly(PyPhEG-co-PyPhON) (10:1) modified SPCE sensors after detection of $10^{4}$ and $5 \times 10^{5} \mathrm{CFU} / \mathrm{ml} \mathrm{E}$. coli and Salmonella lysate, and for measurement on a buffer blank. Each measurement is on a fresh electrode. 
Table 3. Statistical comparisons of bacterial lysates. For the datasets compared, the probability that mean (t-test) and variance (F-test) are the same, assuming normal distributions, and the probability that the distributions are the same using the non-parametric Kolmogorov-Smirnov (K-S) and Mann-Whitney (M-W) tests are shown.

\begin{tabular}{|c|c|c|c|c|c|c|}
\hline & $\begin{array}{c}10^{4} \\
\text { CFU/mL } \\
\text { E. coli } \\
\text { BL21 and } \\
\text { Blank }\end{array}$ & $\begin{array}{c}5 \times 10^{5} \\
\text { CFU/mL } \\
\text { E. coli } \\
\text { BL21 } \\
\text { and } \\
\text { Blank }\end{array}$ & $\begin{array}{c}10^{4} \\
\mathrm{CFU} / \mathrm{mL} \\
\text { Salmonella } \\
\text { and Blank }\end{array}$ & $\begin{array}{c}5 \times 10^{5} \\
\mathrm{CFU} / \mathrm{mL} \\
\text { Salmonella } \\
\text { and Blank }\end{array}$ & $\begin{array}{c}10^{4} \mathrm{CFU} / \mathrm{mL} \\
\text { E. coli BL21 } \\
\text { and } 5 \times 10^{5} \\
\mathrm{CFU} / \mathrm{mL} \\
\text { E. coli BL21 }\end{array}$ & $\begin{array}{l}10^{4} \mathrm{CFU} / \mathrm{mL} \\
\text { E. coli BL21 } \\
\text { and } 10^{4} \\
\mathrm{CFU} / \mathrm{mL} \\
\text { Salmonella }\end{array}$ \\
\hline t-test & $<0.001$ & $<0.001$ & 0.4 & 0.06 & $<0.001$ & $<0.001$ \\
\hline F-test & 0.001 & $<0.001$ & 0.2 & $<0.001$ & 0.09 & 0.003 \\
\hline K-S test & 0.004 & $<0.001$ & 0.6 & 0.009 & $<0.001$ & $<0.001$ \\
\hline$M-W$ test & $<0.001$ & $<0.001$ & 0.3 & 0.001 & $<0.001$ & $<0.001$ \\
\hline
\end{tabular}

The results show that single use electrodes could reliably distinguish $10^{4} \mathrm{CFU} / \mathrm{mL}$ of $E$. coli from the buffer blank. Single use electrodes could also reliably distinguish $5 \times 10^{5} \mathrm{CFU} / \mathrm{mL}$ of $E$. coli BL21 from $10^{4} \mathrm{CFU} / \mathrm{mL}$, and from Salmonella at the same concentration. Salmonella spp. at $5 \times 10^{5} \mathrm{CFU} / \mathrm{mL}$ also gave a result that was statistically significantly greater than the blank, but not at $10^{4} \mathrm{CFU} / \mathrm{mL}$. Given the length of the bacterial genomes (E. cColi: $4.6 \times 10^{6}$ nucleotides; Salmonella: $\sim 4.9 \times 10^{6}$ nucleotides) some cross-sensitivity due to small mismatches with the probe sequence is not surprising. A concentration of $10^{4} \mathrm{CFU} / \mathrm{mL}$ is $\sim 10^{-}$ ${ }^{17} \mathrm{M}$. Passage through the $0.22 \mu \mathrm{m}$ filter would have sheared the DNA, into fragments of unknown length, possibly from as little as 5 kbases but more typically 50 to 100 kbase ${ }^{44-46}$. Thus, the concentration of DNA being detected in the E. coli BL21 bacterial lysate would be on the scale of $10^{-15}-10^{-16} \mathrm{M}$. Overhangs of long fragments hybridised to the surface may themselves hybridise to other fragments, potentially leading to a surface DNA gel, which would account for the change in film capacitance at higher lysate concentration seen for the specific target, E. coli.

\section{(d) Response model for change in film conductivity}

Our results show hybridisation detection primarily through variation in the resistance of the polymer film, with a smaller effect on the rate of the interfacial charge transfer. The effect on the interfacial reaction rate would be consistent with the simple Donnan exclusion mechanism ${ }^{7}$. The effect on the polymer film resistance gives a detectable signal at much lower concentration and is consistent with modulation of charge trapping in the polymer at the polymer-solution interface ${ }^{7,29}$. This is the same mechanism deduced by Wijeratne et al. ${ }^{47}$ for the rate of a redox reaction at a CP-electrolyte interface ${ }^{47}$. The charge transport through the polymer layer is viewed as percolation through a network of junctions between nanoparticulate clusters. Microscopy of the polymer films indeed shows that they comprise a network of nanoparticles of size scale a few $\mathrm{nm}{ }^{29-30}$. The effect of hybridization of DNA to the surface would be to change the charge on the electrolyte side of the semiconductor- 
electrolyte junction. If the DNA charge is not screened by the electrolyte, then a compensating charge would be found on the semiconductor side. According to the classical theory for semiconductor-electrolyte junctions, this charge would be provided by fixed, ionized donor or acceptor states within the semiconductor with an accompanying change in charge carrier concentration ${ }^{48}$. The charge carrier concentration would be modulated near to the interface, and a change in rate of redox reactions would result from this change in charge carrier concentration ${ }^{42}$. This model, however, is not consistent with our results. The charge carriers in the $\mathrm{CP}$ are positive polarons, positively-charged radical cation species, localized on the polymer chain ${ }^{49-50}$. These are also the species that mediate the redox reaction at the interface. A negative surface charge from bound DNA would increase the surface concentration of surface polarons so a decrease in charge transfer resistance at the interface would be expected. This is not observed. Certainly, control of the interfacial reaction rate as a consequence of an increase in uncompensated negative charge contributed by surface-bound DNA is consistent with the results, and explains the very large sensitivity to bacterial lysate, where the captured fragments would be long, giving a large uncompensated bound charge ${ }^{25}$. Therefore, a model relating surface charge to bulk conductivity, in which a negative surface charge causes a decrease in conductivity, is needed. One characteristic of CPs is that the dopant species are ions - negatively charged in this case - which would be mobile within the polymer structure, in contrast to the case of a crystalline semiconductor. Hence, a plausible model is that increase of negative surface charge leads to a dipolar charge distribution within the polymer beneath the surface: the surface-bound charge repels the negative donor species from the surface and traps polarons at the surface, decreasing the film conductivity immediately below the surface. The model is a modification of that given by Kannan et al ${ }^{29}$. The effect will depend on the nanostructure of the CP film - the effect could be more marked at junctions between nanocrystals - and the effect might be very variable across the surface and variable in depth below the surface.

\section{(e) Interpretation through the study of random resistor networks}

Figure 4 shows that the distribution of film resistance approximated log-normal. This distribution arises in the description of many natural phenomena because many natural growth processes are driven by the accumulation of many small percentage changes which become additive on a log scale ${ }^{51}$. In this case, the determining process is assumed to be the random assembly of polymer nanoparticles, as envisaged by Wijeratne et al. If the conductivity between individual particles was controlled by an activation barrier, with barrier height uniformly distributed, then the individual conductivities would be log-normally distributed. The resistance exhibited by individual realisations of the assembly of particles would therefore itself expected to be log-normally distributed. However, an effect of the distribution of individual resistances might be the occurrence of 'critical paths' of low resistance, analogous to a percolation threshold. A true percolation threshold as described by Wijeratne et al. was not observed in the present work ${ }^{47}$. Kirkpatrick ${ }^{52}$ studied the properties of a cubic array of resistors. When the resistance values are sampled at random from an appropriately chosen distribution, the effect of 'critical paths' may be observed. However, a percolation threshold as such may not be found as a consequence of the varying importance of current flow along 'non-critical paths'52. In order to understand further the 
properties of the CP film as a sensor, we have explored the distribution of resistance observed for a cubic network of resistors, where each resistor value is drawn at random from a lognormal distribution. Two features are of note from Figure 4: the distribution is broad; and there is a slight shift to higher resistance of the modal resistance of the experimental results from the modal resistance of the best-fitting log-normal. Results for the simulation using a cubic network of resistors are given in Figure 7. These showed: (1) that to obtain a broad distribution as observed experimentally, the underlying distribution of resistances of the network connections needed to be extremely broad (standard deviation of $\ln ($ resistance) $\approx 6$ ); (2) that as the underlying resistance distribution broadened, the mode of the observed resistance distribution shifted to higher resistance than the mode of the fitted log-normal there was a tail to the distribution at lower resistance.
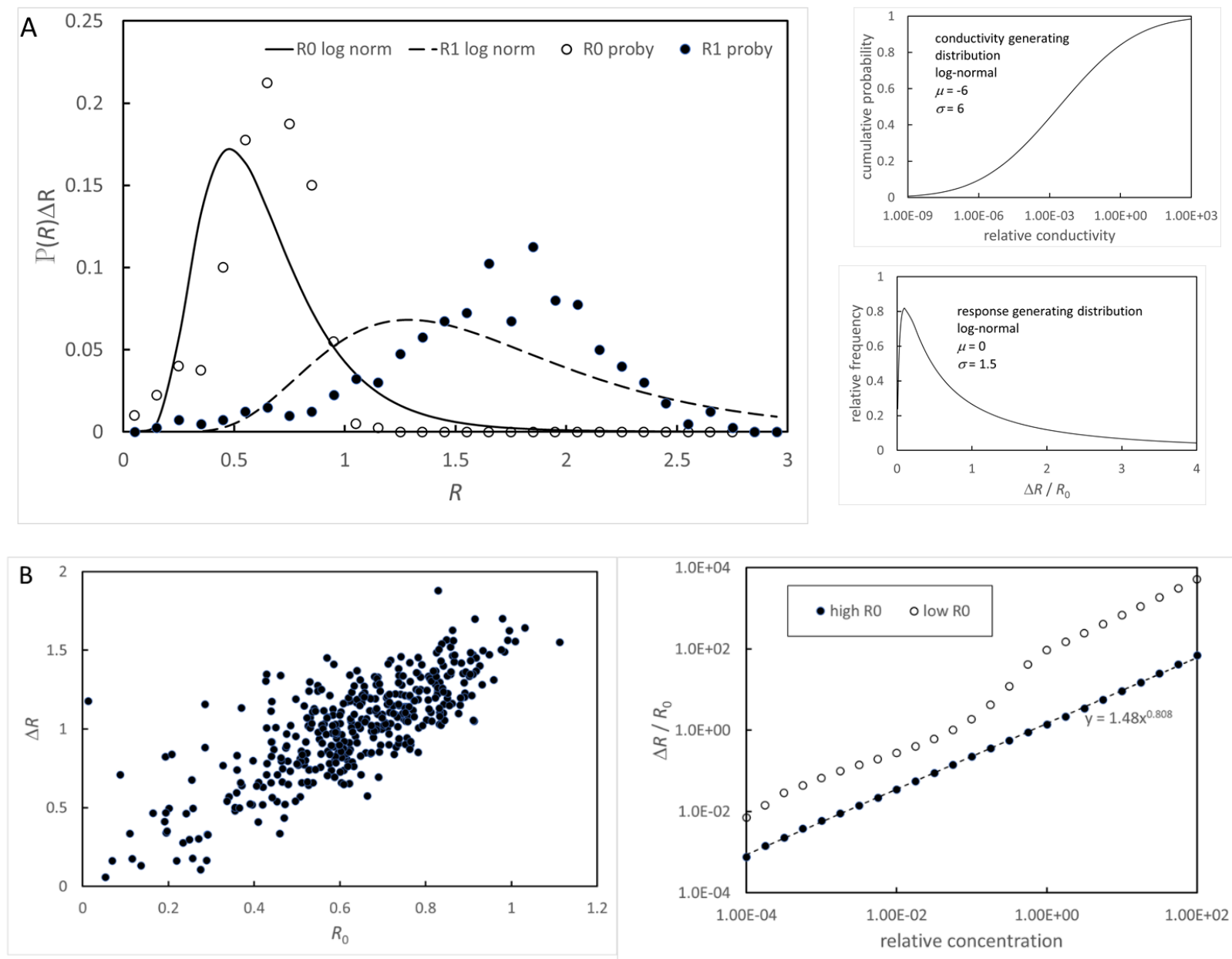

Figure 7. Model response for $50^{3}$ cubic array of resistors where the resistance (conductance) of each individual resistor is drawn at random from a log-normal distribution, and the relative resistance change representing the response is also drawn at random from a log-normal distribution, evaluated for 400 different realisations. (A) Resistance distributions for the 'zero' , $R_{0}$, and 'response', $R_{1}$. Inset: conductance distribution and relative response distribution of individual elements of the array; (B) Resistance change $\Delta R$ and relative 
resistance change $\Delta R / R_{0}$ caused by the imposed response according to the response distribution in (A), (left), against the 'zero' resistance, $R_{0}$, for each of the 400 realisations, for relative concentration $C=1$, and (right) against relative concentration according to the assumed linear response law for each resistor in the network $\Delta R / R_{0}=s C$ where $\mathrm{s}$ denotes the sensitivity drawn from the distribution in $(A)$ - the two curves are for cubes with $R_{0}$ at the lower and upper values found in the set.

These distributions show the effect of 'critical paths' through the cube: rare paths where the faces of the cube are connected predominantly through low-value resistors. The effect is signaled by the appearance in the distribution of a tail to low values of resistance. The tail becomes more marked as a consequence of the imposition of a 'response': the random formation of critical paths becomes more important as a consequence of the random increase in value of the resistors in the network relative to their unperturbed value. These effects can arguably be discerned in the experimental distributions.

\section{(f) Model for logarithmic dependence on solution oligonucleotide concentration}

A logarithmic effect of solution oligonucleotide concentration was observed experimentally, giving rise to a very wide dynamic range. If a linear response model is assumed for the resistances in the network, then a power-law response for the network is obtained, as generally found for resistor network models ${ }^{52-53}$ and as shown by other types of conductimetric sensors ${ }^{54}$. Figure $7 \mathrm{~B}$ shows this, and also shows that the response is modified for realisations where the resistance is low and hence dominated by critical paths. The logarithmic response to solution $\mathrm{ON}$ concentration is not therefore captured by the random resistor model with a uniform response of all resistors in the network. A logarithmic response requires a logarithmic dependence of the resistance of individual elements of the network. The model developed above requires then a logarithmic dependence on solution concentration of $\mathrm{ON}$ of the uncompensated surface charge resulting from ON binding. A potential explanation comes from consideration of the adsorption isotherm describing the ON binding. A simple model is a Temkin-type isotherm, where the adsorption free energy depends on surface coverage, in this case through variation of the surface charge causing a variation of the surface potential with respect to the bulk solution:

$$
\theta /(1-\theta) \approx c \exp \left(-\left(\Delta G_{\text {ads }}^{0}+\left(\left(z e n_{\max } \theta\right)^{2} / C_{\text {interface }}\right)\right)\right)
$$

Here, $\theta$ denotes the fractional coverage of surface binding sites by $\mathrm{ON}$, and the bound surface charge is thus $q \theta$, where $q$ is the charge per bound molecule; $c$ denotes the solution concentration of $\mathrm{ON}, \Delta \mathrm{G}_{\mathrm{ads}}{ }^{0}$ the adsorption Gibbs energy at zero coverage. The additional charge bound to the surface, $q=z e n_{\max } \theta$ where $e$ is the electronic charge, $z$ the charge per bound molecule and $n_{\max }$ the number of bound molecules per unit area at full coverage ( $\theta=$ 1). The term $\left(\left(\text { zen }_{\max } \theta\right)^{2} / C_{\text {interface }}\right)=\left(q^{2} \theta / C_{\text {interface }}\right)$ accounts for the effect on the binding energy as the surface charge increases, increasing the surface potential. It increases rapidly as the surface coverage increases. At very low coverage, equation 1 gives a linear dependence of coverage (hence bound charge) on concentration. However, the effect of the 
surface potential change soon begins to dominate, especially if $z$ is large, as is the case with bound oligonucleotides or DNA fragments, giving rise to a logarithmic dependence of bound charge on solution concentration, making the model developed above consistent with the experimental observations.

\section{(g) Significance of the results}

The significance of the results is that a highly sensitive and specific DNA detection, previously demonstrated to be compatible with PCR amplification and offering detection of low copy numbers with few amplification cycles ${ }^{30}$, is achieved with a device which is massmanufacturable at low cost. The concept design shown in figure 8 is based on the results given here and those reported in ref 30 . The main issue for the sensors is the distribution of sensitivity for different electrodes. The modelling indicates that this may be an inherent characteristic of these sensors, dependent on the control of nanostructure in the electropolymerized film, and dependent on the uniformity or otherwise of response across the connections between CP nanoparticles that are assumed to control the film resistance.

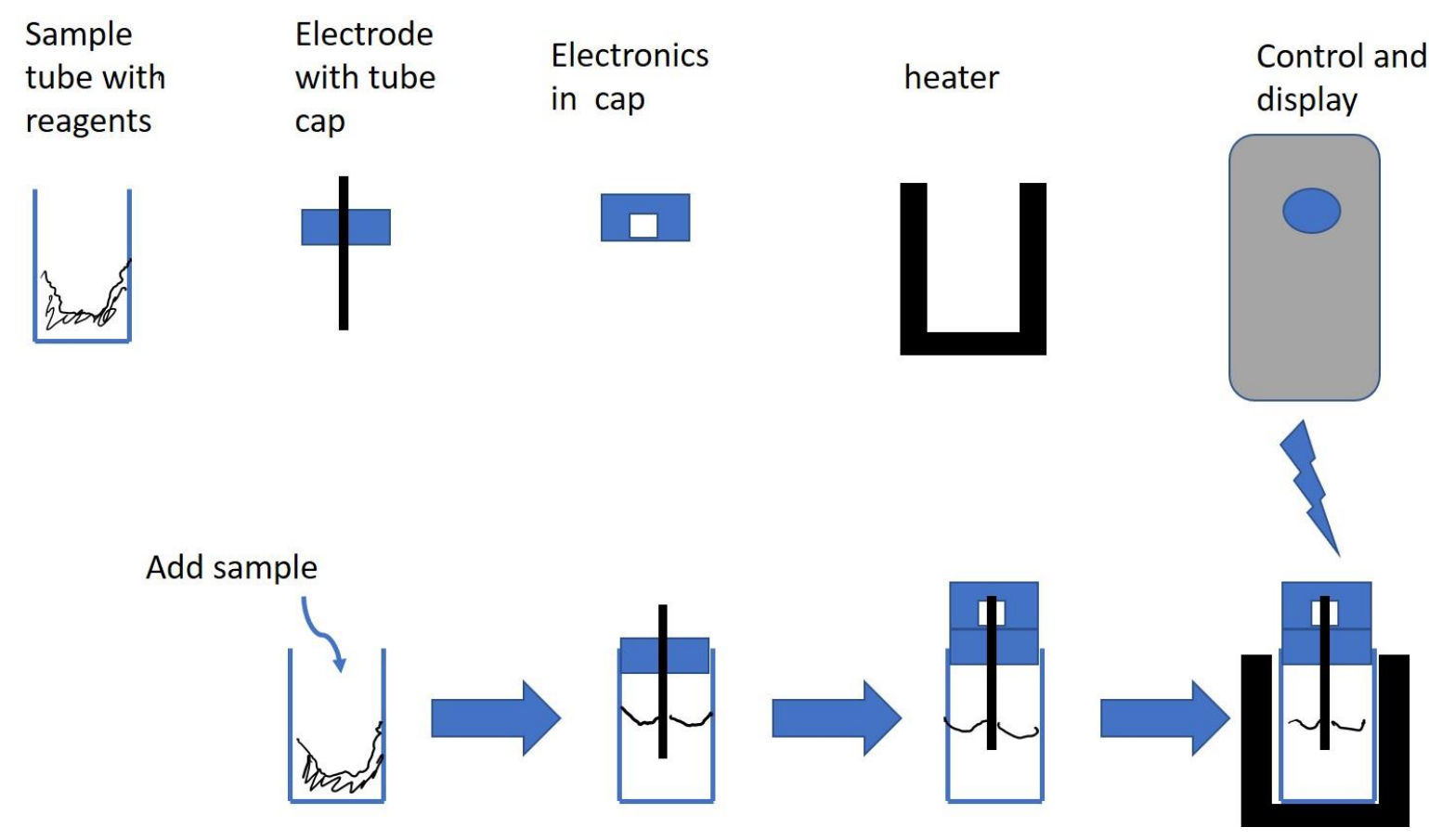

Figure 8. Design concept for rapid, point-of-use measurement using e-PCR

Variation across the surface in the electropolymerisation reaction rate could lead to areas that are either imperfectly decorated with $\mathrm{CP}$, or not decorated at all, or sites where the modifying probe $\mathrm{ON}$ has been in part buried within a thicker layer of the polymer. Polymer nanostructure, coverage and thickness, and local probe density would affect the local value of $R_{\text {film }, 0}$ and local exposed probe density would affect the signal, $\triangle R_{\text {film }} / R_{\text {film }, 0}$. Variability of the electropolymerisation may be connected to variability of transport and reaction across the electrode surface, particularly porosity, cracks and any variations in the type of carbon exposed. A further possible artifact is non-specific adsorption of oligonucleotides causing a 
time-dependent wetting in cracks and porosity. Screen-printing inks from different manufacturers vary in the detailed composition of the carbon and the binders, and the surface composition; specifically, the ratio of carbon to binder exposed at the surface, as well as the porosity, varies with the details of the printer setup as well as with details of methodology in mixing and drying. Improvements in manufacture can be anticipated, however, given that the possibility of mass-manufacture has now been demonstrated. Other studies have reported methods such as oxygen plasma treatment or laser surface glazing as routes to improve repeatability ${ }^{55-56}$. Given that screen-printed carbon might produce intrinsically unreliable electrodes ${ }^{57}$, other carbon-based electrode fabrication technologies, such as laser-scribing of graphene on flexible substrates ${ }^{58-59}$ may provide superior alternatives, or electrodes such as gold-coated mylar could be considered.

\section{Conclusion}

We have demonstrated the fabrication at significant scale of a portable, single-use DNAsensing strip with very high detection sensitivity based on poly(PyPhEG-co-PyPhON)-modified screen-printed electrodes. The poly(PyPhEG-co-PyPhON) was electropolymerised from the ON probe pre-attached monomer. We have shown that the signal is generated as a result of the surface charge-dependence of the polymer film resistance and have described a model for the response based on percolation in a random resistor array.

Statistically significant detection at $1 \mathrm{pM}$ ss-ON concentration has been demonstrated for 82 single-use sensor strips (and selectivity with another $>80$ sensor strips), independently measured. Statistically significant detection of DNA in bacterial lysate has been demonstrated at $10^{4} \mathrm{CFU} / \mathrm{mL}$ (concentration on $\mathrm{fM}-\mathrm{aM}$ scale) for single-use sensor strips. In titration experiments on particular strips, the detection limit was lower. In general, SPCEs with poly(PyPhEG-Co-PyPhON) modification as a basis for these biosensors show potential for detection of DNA with simple, portable instrumentation and single-use sensor strips. Precise control of nanostructure and capture-probe exposure in the electropolymerized films is a key challenge to overcome. The method is suitable for low-cost industrial-scale fabrication, and the detection sensitivity and selectivity could be further extended by the use of these devices in conjunction with the previously-described electrochemical PCR method ${ }^{30}$.

\section{Experimental}

\section{Materials}

Dimethylformamide (DMF), tetrahydrofuran (THF), phosphate buffered saline (PBS) pellets, sodium para toluene sulfonate ( $\mathrm{NaToS})$, potassium ferricyanide $\left(\mathrm{K}_{3}\left[\mathrm{Fe}(\mathrm{CN})_{6}\right]\right)$, potassium ferrocyanide $\left(\mathrm{K}_{4}\left[\mathrm{Fe}(\mathrm{CN})_{6}\right]\right), \quad \mathrm{N}$-hydroxysuccinimide $(\mathrm{NHS}), \quad$ and 1-ethyl-3-(3dimethylaminopropyl) carbodiimide (EDC) were purchased from Sigma Aldrich. The carbon ink for screen-printed electrodes, BQ242, was purchased from DuPont. Kapton tape (No. 4362778) and Mylar sheets (250 $\mu \mathrm{m}$, No. 785-0802) were purchased from RS Components. Oligonucleotides (Table 1) were purchased from Alpha DNA. Phosphate-buffered saline solution (PBS) was prepared by dissolving a PBS tablet (P4417-100TAB, Sigma-Aldrich Ltd.) into $200 \mathrm{~mL}$ deionised water (Milli Q, 18.2 M $\mathrm{M} . \mathrm{cm}$ at $25^{\circ} \mathrm{C}$ ). Half-strength PBS (HPB) was made by mixing $200 \mathrm{~mL}$ PBS with $200 \mathrm{~mL}$ deionised water. Synthesis of (6,6'-((2,5-di(1H-pyrrol-2-yl)- 
1,4-phenylene)bisoxy)) dihexanoic acid (PyPhCOOH) and 2,2'-(2,5-bis(2-(2-(2methoxyethoxy)ethoxy)ethoxy)-1,4-phenylene) tripyrrole (PyPhEG) was as described previously ${ }^{60}$. The $\mathrm{ON}$ probes were attached to the carboxylic acid groups on $\mathrm{PyPhCOOH}$, as detailed below in section 2.3. PyPhEG was used as a co-monomer with PyPh-ON, on the presumption (not further investigated in this work) that the ethylene glycol units on PyPhEG would afford some antifouling properties to the sensing film ${ }^{61}$.

Table 1. Sequences of synthetic oligonucleotide probes and targets used.

\begin{tabular}{lll}
\hline Oligonucleotide & Modification & DNA sequences (5'-3') \\
\hline Single-stranded (ss)-ON probe & $5^{\prime}$ amino & GGAAGGATCGACAGATTTGATC \\
Complementary ON target (C-ON) & None & GATCAAATCTGTCGATCCTTCC \\
$\begin{array}{l}\text { Non-complementary ON target } \\
\text { (Nc-ON) }\end{array}$ & AGne & \\
Probe specific to E. coli BL 21 & 5' amino & GGAAGGATCGACAGATTTGATC \\
\hline
\end{tabular}

\section{Fabrication of screen-printed carbon electrodes (SPCE)}

The sensor fabrication steps are presented in Scheme 1. The electrodes were designed to have a $2 \mathrm{~mm}$ diameter working electrode (WE), a reference electrode (RE) and a counter electrode (CE), as shown in the photograph in the Scheme 1(B). The carbon layer for all three electrodes was printed using BQ 242 carbon ink on a Mylar substrate, using a screen-printer (DEK1202) with manual control of the squeegee, as shown in Scheme 1(A i). The printed electrodes were cured in an oven at $130^{\circ} \mathrm{C}$ for $15 \mathrm{~min} . \mathrm{Ag} / \mathrm{AgCl}$ ink was brushed onto the end of the printed carbon RE (ca. $2 \mathrm{~mm}$ ), then cured at $130^{\circ} \mathrm{C}$ for $20 \mathrm{~min}$. Kapton tape, as an insulating layer, was applied to cover the electrode tracks, excluding the contact pads (Scheme 1 (A ii)). As shown in Scheme 1(C), scanning electron microscopy (SEM) revealed the rough morphology of the SPCE surface. The electrochemically-estimated real surface area of the SPCEs (Supporting Information, $\mathrm{SI}$ ) was $0.043 \pm 0.003 \mathrm{~cm}^{2}$, indicating a roughness factor of $1.4 \pm 0.1$.

\section{Attachment of ss-ON probes to PyPhCOOH monomer and electropolymerisation of the sensing CP layer onto SPCE}

Covalent attachment of the single-stranded (ss-ON) probe to $\mathrm{PyPhCOOH}$ monomer is described in detail in ${ }^{6}$. In short, $100 \mu \mathrm{L}$ of $200 \mu \mathrm{M} \mathrm{PyPhCOOH}$ monomer in THF solution was incubated with $100 \mu \mathrm{l}$ of PBS (pH 6.5) containing EDC (20 mM) and NHS (10 mM) at $28^{\circ} \mathrm{C}$ for $1 \mathrm{~h}$ under $\mathrm{N}_{2}$, followed by addition of $100 \mu \mathrm{L}$ of $1 \mathrm{mM}$ ss-ON probe for another $1 \mathrm{~h}{ }^{25}$. After ON probe attachment, THF was evaporated under $\mathrm{N}_{2}$ and the remaining aqueous solution, without further purification, was stored at $-20{ }^{\circ} \mathrm{C}$ and used within $24 \mathrm{~h}$. The final electropolymerisation solution contained $50 \mu \mathrm{M}$ PyPhON, $500 \mu \mathrm{M}$ PyPhEG, and $0.1 \mathrm{M}$ sodium para-toluene sulfonate (NaToS) in $2 \mathrm{ml} \mathrm{DMF/PBS} \mathrm{(1:1),} \mathrm{giving} \mathrm{a} \mathrm{PyPhEG:PhPyON} \mathrm{ratio} \mathrm{of} \mathrm{10:1.}$ DMF was included to aid solubility of the co-monomer PyPhEG. For a 50:1 ratio, to afford a lower probe density, the concentration of PyPhEG monomer was kept at $500 \mu \mathrm{M}$, while the PyPhON concentration was adjusted accordingly. Before electropolymerisation, $20 \mu \mathrm{L}$ of the monomer solution was pipetted onto the SPCE, fully covering the WE, RE and CE. A potential 
of $0.8 \mathrm{~V}$ was applied to the WE for $30 \mathrm{~s}$, unless otherwise stated, to electropolymerise the CP film onto the WE. The charge passed was $0.16 \pm 0.04 \mathrm{mC}$, giving an estimated thickness of poly(PyPhEG-co-PyPyON) of $20 \pm 5 \mathrm{~nm}$, assuming uniform surface coverage. The estimation of thickness is provided in the SI. Scheme 2 gives a chemical structure model for the polymer and a model for the charge-transfer reaction at the polymer-solution interface.

A

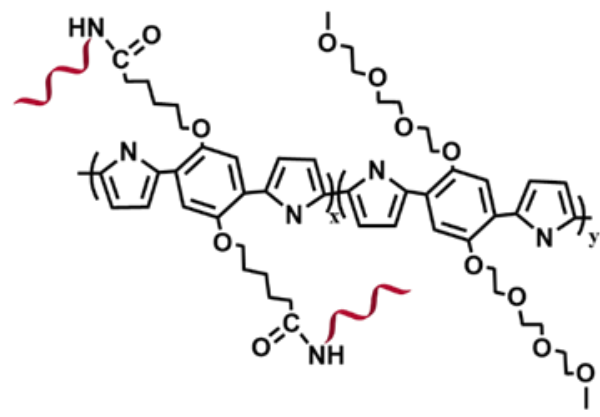

B

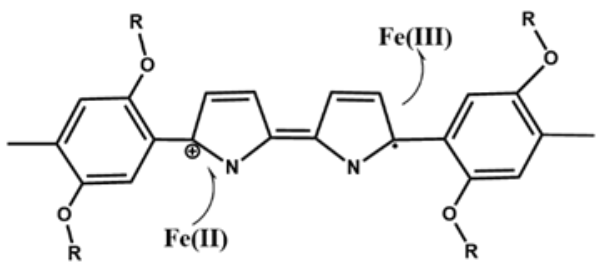

Scheme 2. (A) Chemical structure model for the functionalized CP; (B) Model for the charge transfer reaction between solution redox couple and oxidized polymer.

\section{Detection of synthetic ss-ONs as target DNA}

As shown in Scheme 1 (A iv), poly(PyPhEG-co-PyPhON)-based sensors were first incubated in HPB for 5 min prior to target ON detection. The EIS readout (see below) from this step was used as the baseline $\left(R_{\mathrm{ct}}{ }^{0}\right)$ to normalize the EIS signal to the ON target solutions. Poly(PyPhEGco-PyPhON) modified SPCE was incubated with $100 \mu \mathrm{L}$ ON target solutions in HPB (in $1.5 \mathrm{~mL}$ Eppendorf vials) at $39.5^{\circ} \mathrm{C}$ for 5 min (unless otherwise stated).

The electrodes were then washed with HPB and EIS measurements undertaken in a $20 \mu \mathrm{L}$ drop of $\mathrm{K}_{3}\left[\mathrm{Fe}(\mathrm{CN})_{6}\right] / \mathrm{K}_{4}\left[\mathrm{Fe}(\mathrm{CN})_{6}\right](10 \mathrm{mM}$ each) redox couple in HPB deposited on the sensor surface. The impedance data were measured and collected over a frequency range from $1 \mathrm{~Hz}$ to $100 \mathrm{kHz}$, with $10 \mathrm{mV}$ sinusoidal excitation amplitude at an applied bias potential of $0.14 \mathrm{~V}$ vs. $\mathrm{Ag} / \mathrm{AgCl}$ (painted) as RE. The bias potential was determined from the $\mathrm{CV}$ measurements of poly(PyPhEG-co-PyPhON) modified SPCE as the potential of zero net current, as shown in Figure S1. In total, 85 and 81 independent sensors were tested for C-ON and Nc-ON, respectively. For titration measurements, working up from the lowest to the highest concentration, a single electrode was used, progressively repeating the sequence: removal of the drop of redox couple solution, washing of the electrode, incubation with the next oligonucleotide solution, then finally measurement in the redox couple solution.

\section{Detection of specific DNA in bacterial lysates}

The bacterial lysates were kindly supplied by Assoc. Prof. Simon Swift (The University of Auckland, Department of Molecular Medicine and Pathology). E. coli BL21 was used as the complementary 'target' and Salmonella enterica serovar Typhimurium (obtained from ATCC: https://www.atcc.org/products/all/14028.aspx\#generalinformation) as the noncomplementary control. A short probe sequence (Table 1) was designed by comparison of the known genomic sequences to be fully complementary to a 22 -mer sequence found in $E$. coli 
BL21 with only partial complementarity to Salmonella (for at most 10 of the 22 nucleotides). The lysates were prepared by heating live bacterial solutions at $95^{\circ} \mathrm{C}$ for $5 \mathrm{~min}$ and filtering through a $0.22 \mu \mathrm{m}$ syringe filter before further dilution in HPB. After the EIS baseline was measured in a $20 \mu \mathrm{L} \mathrm{HPB}$ drop containing $\mathrm{K}_{3}\left[\mathrm{Fe}(\mathrm{CN})_{6}\right] / \mathrm{K}_{4}\left[\mathrm{Fe}(\mathrm{CN})_{6}\right](10 \mathrm{mM}$ each) redox couple, $50 \mu \mathrm{L}$ of the bacterial lysate was heated at $95^{\circ} \mathrm{C}$ for 5 min to denature dsDNA ${ }^{62}$. This was then mixed immediately with room temperature deionised water in a $1.5 \mathrm{~mL}$ Eppendorf tube to dilute as required. Mixing decreased the solution temperature to approximately $60^{\circ} \mathrm{C}$. Poly(PyPhEG-co-PyPhON)-modified SPCE was then immediately dipped into the solution and incubated at $39.5^{\circ} \mathrm{C}$ for $5 \mathrm{~min}$. The electrodes were then washed with HPB and EIS measurements were carried out in a $20 \mu \mathrm{L}$ drop of $\mathrm{K}_{3}\left[\mathrm{Fe}(\mathrm{CN})_{6}\right] / \mathrm{K}_{4}\left[\mathrm{Fe}(\mathrm{CN})_{6}\right](10 \mathrm{mM}$ each) redox couple in HPB deposited on the sensor surface.

\section{Quartz crystal microbalance with dissipation (QCM-D) measurements}

Gold (100 nm thick) coated quartz crystals (QSX301) were sonicated sequentially in ethanol and deionized water (Milli-Q, 18.2 M $2 . \mathrm{cm}$ at $25^{\circ} \mathrm{C}$ ) for $15 \mathrm{~min}$ each. A 5:1:1 vol ratio solution of deionized water, ammonia (25\%) and hydrogen peroxide (30\%) was heated to $75{ }^{\circ} \mathrm{C}$ and the sonicated quartz crystals were then added for $5 \mathrm{~min}$. The crystals were then removed from the solution and rinsed thoroughly with deionised water before being dried with nitrogen gas ${ }^{63}$. A Poly(PyPhEG-co-PyPhON) film was then electropolymerized onto the surface of the cleaned gold-coated crystals after which they were transferred to the chamber of a Q-sense analyzer instrument (Biolin Scientific). Solutions of ON-targets or Non-ON targets in HPB were introduced into the chamber and allowed to bind with the ON probes on the poly(PyPhEG-co-PyPhON) film. The flow rate of all tested solutions was continuous at $65 \mu \mathrm{L} / \mathrm{h}$ for all the steps. The changes in quartz crystal frequency $(\Delta f)$ and dissipation $(D)$ were measured.

\section{Computational method}

The sensor was modelled as a $50^{3}$ array of resistors drawn at random from a log-normal distribution. The conductance between opposite faces of the cube, applying cyclic boundary conditions for the other cube faces, was calculated using the relaxation method of Kirkpatrick ${ }^{53}$, as described in detail by Williams and Pratt ${ }^{64} .400$ different realisations of a random array with given mean and standard deviation were computed. Response was computed by altering the resistance change between each node relative to the unaltered resistance, with the magnitude of the relative change between each node also drawn at random from a lognormal distribution. Calculations were performed using VBA within an Excel spreadsheet. The spreadsheet with code and example results is given in the SI.

\section{Acknowledgement:}

We would like thank Dr Nitish Dhirubhai Patel from The University of Auckland, Dept of Electrical and Computer Engineering for his assistance with equipment. This work was funded by Auckland Uniservices Ltd and the MacDiarmid Institute for Advanced Materials and Nanotechnology, New Zealand.

\section{Corresponding Authors:}


David E. Williams: School of Chemical Sciences, The University of Auckland, 23 Symonds Street, Auckland 1010, New Zealand; MacDiarmid Institute for Advanced Materials and Nanotechnology, Victoria University of Wellington, Laby Building Kelburn Campus Victoria University of Wellington, Wellington 6012, New Zealand.

Email: david.williams@auckland.ac.nz

Jadranka Travas-Sejdic: Polymer Biointerface Centre, School of Chemical Sciences, The University of Auckland, 23 Symonds Street, Auckland 1010, New Zealand; MacDiarmid Institute for Advanced Materials and Nanotechnology, Victoria University of Wellington, Laby Building Kelburn Campus Victoria University of Wellington, Wellington 6012, New Zealand

Email: j.travas-sejdic@auckland.ac.nz

\section{Author information}

Bicheng Zhu: Polymer Biointerface Centre, School of Chemical Sciences, The University of Auckland, 23 Symonds Street, Auckland 1010, New Zealand; MacDiarmid Institute for Advanced Materials and Nanotechnology, Victoria University of Wellington, Laby Building Kelburn Campus Victoria University of Wellington, Wellington 6012, New Zealand.

Email: Bicheng.zhu@auckland.ac.nz

Thomas Kerr-Philips: Polymer Biointerface Centre, School of Chemical Sciences, The University of Auckland, 23 Symonds Street, Auckland 1010, New Zealand

Email: tker016@aucklanduni.ac.nz

Zahraa Al Ghaus: Polymer Biointerface Centre, School of Chemical Sciences, The University of Auckland, 23 Symonds Street, Auckland 1010, New Zealand

Email: zjar046@aucklanduni.ac.nz

Eddie Wai Chi Chan: Polymer Biointerface Centre, School of Chemical Sciences, The University of Auckland, 23 Symonds Street, Auckland 1010, New Zealand; MacDiarmid Institute for Advanced Materials and Nanotechnology, Victoria University of Wellington, Laby Building Kelburn Campus Victoria University of Wellington, Wellington 6012, New Zealand.

Email: eddie.chan@auckland.ac.nz

David Barker: Polymer Biointerface Centre, School of Chemical Sciences, The University of Auckland, 23 Symonds Street, Auckland 1010, New Zealand; MacDiarmid Institute for Advanced Materials and Nanotechnology, Victoria University of Wellington, Laby Building Kelburn Campus Victoria University of Wellington, Wellington 6012, New Zealand.

Email: d.barker@auckland.ac.nz

Clive W. Evans: School of Biological Sciences, The University of Auckland, 24 Symonds Street, Auckland 1010, New Zealand

Email: c.evans@auckland.ac.nz 


\section{Reference:}

1. Peng, H.; Zhang, L.; Soeller, C.; Travas-Sejdic, J., Conducting polymers for electrochemical DNA sensing. Biomaterial.s 2009, 30 (11), 2132-2148.

2. Naveen, M. H.; Gurudatt, N. G.; Shim, Y.-B., Applications of conducting polymer composites to electrochemical sensors: A review. Appl. Mater. Today. 2017, 9, 419-433.

3. Ramanavičius, A.; Ramanavičienè, A.; Malinauskas, A., Electrochemical sensors based on conducting polymer-polypyrrole. Electrochim. Acta. 2006, 51 (27), 6025-6037.

4. Aydemir, N.; Malmström, J.; Travas-Sejdic, J., Conducting polymer based electrochemical biosensors. Phys. Chem. Chem. Phys. 2016, 18 (12), 8264-8277.

5. Travas-Sejdic, J.; Aydemir, N.; Kannan, B.; Williams, D. E.; Malmström, J., Intrinsically conducting polymer nanowires for biosensing. J Mater Chem B. 2014, 2 (29), 4593-4609.

6. Aydemir, N.; Chan, E.; Baek, P.; Barker, D.; Williams, D. E.; Travas-Sejdic, J., New immobilisation method for oligonucleotides on electrodes enables highly-sensitive, electrochemical label-free gene sensing. Biosens. Bioelectron. 2017, 97, 128-135.

7. Kannan, B.; Williams, D. E.; Booth, M. A.; Travas-Sejdic, J., High-Sensitivity, Label-Free DNA Sensors Using Electrochemically Active Conducting Polymers. Anal. Chem. 2011, 83 (9), 3415-3421.

8. Kerr-Phillips, T. E.; Aydemir, N.; Chan, E. W. C.; Barker, D.; Malmström, J.; Plesse, C.; TravasSejdic, J., Conducting electrospun fibres with polyanionic grafts as highly selective, label-free, electrochemical biosensor with a low detection limit for non-Hodgkin lymphoma gene. Biosens. Bioelectron. 2018, 100, 549-555.

9. Peng, H.; Soeller, C.; Vigar, N.; Kilmartin, P. A.; Cannell, M. B.; Bowmaker, G. A.; Cooney, R. P.; Travas-Sejdic, J., Label-free electrochemical DNA sensor based on functionalised conducting copolymer. Biosens. Bioelectron. 2005, 20 (9), 1821-1828.

10. Korri-Youssoufi, H.; Garnier, F.; Srivastava, P.; Godillot, P.; Yassar, A., Toward Bioelectronics: Specific DNA Recognition Based on an Oligonucleotide-Functionalized Polypyrrole. J. Am. Chem. Soc. 1997, 119 (31), 7388-7389.

11. Thompson, L. A.; Kowalik, J.; Josowicz, M.; Janata, J., Label-Free DNA Hybridization Probe Based on a Conducting Polymer. J. Am. Chem. Soc. 2003, 125 (2), 324-325.

12. de Boer, E.; Beumer, R. R., Methodology for detection and typing of foodborne microorganisms. Int. J. Food Microbiol. 1999, 50 (1), 119-130.

13. Darain, F.; Park, S.-U.; Shim, Y.-B., Disposable amperometric immunosensor system for rabbit IgG using a conducting polymer modified screen-printed electrode. Biosens. Bioelectron. 2003, 18 (5), 773-780.

14. Bangar, M. A.; Shirale, D. J.; Chen, W.; Myung, N. V.; Mulchandani, A., Single Conducting Polymer Nanowire Chemiresistive Label-Free Immunosensor for Cancer Biomarker. Anal. Chem. 2009, 81 (6), 2168-2175.

15. Zhu, B.; Alsager, O. A.; Kumar, S.; Hodgkiss, J. M.; Travas-Sejdic, J., Label-free electrochemical aptasensor for femtomolar detection of $17 \beta$-estradiol. Biosens. Bioelectron. 2015, 70, 398-403.

16. Park, S. J.; Lee, J.; Seo, S. E.; Kim, K. H.; Park, C. S.; Lee, S. H.; Ban, H. S.; Lee, B. D.; Song, H. S.; Kim, J.; Lee, C.-S.; Bae, J.; Kwon, O. S., High-Performance Conducting Polymer Nanotube-based LiquidIon Gated Field-Effect Transistor Aptasensor for Dopamine Exocytosis. Sci. Rep. 2020, 10 (1), 3772.

17. Sargent, A.; Sadik, O. A., Monitoring antibody-antigen reactions at conducting polymer-based immunosensors using impedance spectroscopy. Electrochim. Acta. 1999, 44 (26), 4667-4675.

18. Sheikhzadeh, E.; Chamsaz, M.; Turner, A. P. F.; Jager, E. W. H.; Beni, V., Label-free impedimetric biosensor for Salmonella Typhimurium detection based on poly [pyrrole-co-3-carboxyl-pyrrole] copolymer supported aptamer. Biosens. Bioelectron. 2016, 80, 194-200.

19. Gębala, M.; Schuhmann, W., Controlled Orientation of DNA in a Binary SAM as a Key for the Successful Determination of DNA Hybridization by Means of Electrochemical Impedance Spectroscopy. ChemPhysChem. 2010, 11 (13), 2887-2895. 
20. Yang, Y.; Li, C.; Yin, L.; Liu, M.; Wang, Z.; Shu, Y.; Li, G., Enhanced Charge Transfer by Gold Nanoparticle at DNA Modified Electrode and Its Application to Label-Free DNA Detection. ACS Appl. Mater. Interfaces. 2014, 6 (10), 7579-7584.

21. Hu, K.; Lan, D.; Li, X.; Zhang, S., Electrochemical DNA Biosensor Based on Nanoporous Gold Electrode and Multifunctional Encoded DNA-Au Bio Bar Codes. Anal. Chem. 2008, 80 (23), 9124-9130. 22. Hong, N.; Cheng, L.; Wei, B.; Chen, C.; He, L. L.; kong, D.; Ceng, J.; Cui, H.-F.; Fan, H., An electrochemical DNA sensor without electrode pre-modification. Biosens. Bioelectron. 2017, 91, 110114.

23. Vogiazi, V.; de la Cruz, A.; Heineman, W. R.; White, R. J.; Dionysiou, D. D., Effects of Experimental Conditions on the Signaling Fidelity of Impedance-Based Nucleic Acid Sensors. Anal. Chem. 2021, 93 (2), 812-819.

24. Tajik, S.; Beitollahi, H.; Nejad, F. G.; Shoaie, I. S.; Khalilzadeh, M. A.; Asl, M. S.; Van Le, Q.; Zhang, K.; Jang, H. W.; Shokouhimehr, M., Recent developments in conducting polymers: applications for electrochemistry. RSC Adv. 2020, 10 (62), 37834-37856.

25. Booth, M. A.; Harbison, S.; Travas-Sejdic, J., Development of an electrochemical polypyrrolebased DNA sensor and subsequent studies on the effects of probe and target length on performance. Biosens. Bioelectron. 2011, 28 (1), 362-367.

26. Zhu, B.; Travas-Sejdic, J., PNA versus DNA in electrochemical gene sensing based on conducting polymers: study of charge and surface blocking effects on the sensor signal. Analyst 2018, $143(3), 687-694$.

27. Kjällman, T. H. M.; Peng, H.; Soeller, C.; Travas-Sejdic, J., Effect of Probe Density and Hybridization Temperature on the Response of an Electrochemical Hairpin-DNA Sensor. Anal. Chem. 2008, 80 (24), 9460-9466.

28. Lacina, K.; Sopoušek, J.; Čunderlová, V.; Hlaváček, A.; Václavek, T.; Lacinová, V., Biosensing based on electrochemical impedance spectroscopy: Influence of the often-ignored molecular charge. Electrochem. commun. 2018, 93, 183-186.

29. Kannan, B.; Williams, D. E.; Laslau, C.; Travas-Sejdic, J., A highly sensitive, label-free gene sensor based on a single conducting polymer nanowire. Biosens. Bioelectron. 2012, 35 (1), 258-264.

30. Aydemir, N.; McArdle, H.; Patel, S.; Whitford, W.; Evans, C. W.; Travas-Sejdic, J.; Williams, D. E., A Label-Free, Sensitive, Real-Time, Semiquantitative Electrochemical Measurement Method for DNA Polymerase Amplification (ePCR). Anal. Chem. 2015, 87 (10), 5189-5197.

31. Farabullini, F.; Lucarelli, F.; Palchetti, I.; Marrazza, G.; Mascini, M., Disposable electrochemical genosensor for the simultaneous analysis of different bacterial food contaminants. Biosens. Bioelectron. 2007, 22 (7), 1544-1549.

32. Liao, J. C.; Mastali, M.; Li, Y.; Gau, V.; Suchard, M. A.; Babbitt, J.; Gornbein, J.; Landaw, E. M.; McCabe, E. R. B.; Churchill, B. M.; Haake, D. A., Development of an advanced electrochemical DNA biosensor for bacterial pathogen detection. J Mol Diagn. 2007, 9 (2), 158-168.

33. Suherman, A. L.; Rasche, B.; Godlewska, B.; Nicholas, P.; Herlihy, S.; Caiger, N.; Cowen, P. J.; Compton, R. G., Electrochemical Detection and Quantification of Lithium lons in Authentic Human Saliva Using LiMn2O4-Modified Electrodes. ACS Sens. 2019, 4 (9), 2497-2506.

34. Pasakon, P.; Mensing, J. P.; Phokaratkul, D.; Karuwan, C.; Lomas, T.; Wisitsoraat, A.; Tuantranont, A., A high-performance, disposable screen-printed carbon electrode modified with multi-walled carbon nanotubes/graphene for ultratrace level electrochemical sensors. J. Appl. Electrochem. 2019, 49 (2), 217-227.

35. Huang, B.; Ji, L.; Liang, B.; Cao, Q.; Tu, T.; Ye, X., A simple and low-cost screen printed electrode for hepatocellular carcinoma methylation detection. Analyst 2019, 144 (10), 3282-3288.

36. Honeychurch, K. C.; Hart, J. P., Screen-printed electrochemical sensors for monitoring metal pollutants. Trends Analyt Chem. 2003, 22 (7), 456-469.

37. Cui, G.; Kim, S. J.; Choi, S. H.; Nam, H.; Cha, G. S.; Paeng, K.-J., A Disposable Amperometric Sensor Screen Printed on a Nitrocellulose Strip: A Glucose Biosensor Employing Lead Oxide as an Interference-Removing Agent. Anal. Chem. 2000, 72 (8), 1925-1929. 
38. González-Sánchez, M. I.; Gómez-Monedero, B.; Agrisuelas, J.; Iniesta, J.; Valero, E., Electrochemical performance of activated screen printed carbon electrodes for hydrogen peroxide and phenol derivatives sensing. J. Electroanal. Chem. 2019, 839, 75-82.

39. Bastos, M.; Castro, V.; Mrevlishvili, G.; Teixeira, J., Hydration of ds-DNA and ss-DNA by Neutron Quasielastic Scattering. Biophys. J. 2004, 86 (6), 3822-3827.

40. Tang, W.; Wang, D.; Xu, Y.; Li, N.; Liu, F., A self-assembled DNA nanostructure-amplified quartz crystal microbalance with dissipation biosensing platform for nucleic acids. Chem. Commun. 2012, 48 (53), 6678-6680.

41. Meléndrez, D.; Jowitt, T.; Iliut, M.; Verre, A. F.; Goodwin, S.; Vijayaraghavan, A., Adsorption and binding dynamics of graphene-supported phospholipid membranes using the QCM-D technique. Nanoscale. 2018, 10 (5), 2555-2567.

42. Hens, Z., The Electrochemical Impedance of One-Equivalent Electrode Processes at Dark Semiconductor|Redox Electrodes Involving Charge Transfer through Surface States. 1. Theory. J. Phys. Chem. B. 1999, 103 (1), 122-129.

43. Lassalle, N.; Mailley, P.; Vieil, E.; Livache, T.; Roget, A.; Correia, J.; Abrantes, L. J. J. o. E. C., Electronically conductive polymer grafted with oligonucleotides as electrosensors of DNA: Preliminary study of real time monitoring by in situ techniques. J. Electroanal. Chem. 2001, 509 (1), 48-57.

44. Klingström, T.; Bongcam-Rudloff, E.; Pettersson, O. V., A comprehensive model of DNA fragmentation for the preservation of High Molecular Weight DNA. bioRxiv. 2018, 254276.

45. Joneja, A.; Huang, X., A device for automated hydrodynamic shearing of genomic DNA. BioTechniques. 2009, 46 (7), 553-556.

46. Quail, M. A., DNA: Mechanical Breakage. In Encyclopedia of Life Sciences (ELS), John Wiley \& Sons, Ltd. 2010

47. Wijeratne, K.; Ail, U.; Brooke, R.; Vagin, M.; Liu, X.; Fahlman, M.; Crispin, X., Bulk electronic transport impacts on electron transfer at conducting polymer electrode-electrolyte interfaces. Proc. Natl. Acad. Sci. U.S.A. 2018, 115 (47), 11899-11904.

48. Zemel, J. N., Semiconductor surface device physics. Sens. Actuators. 1981, 1, 31-75.

49. Brédas, J. L.; Scott, J. C.; Yakushi, K.; Street, G. B., Polarons and bipolarons in polypyrrole: Evolution of the band structure and optical spectrum upon doing. Phys. Rev. B. 1984, 30 (2), $1023-$ 1025.

50. Bredas, J. L.; Street, G. B., Polarons, bipolarons, and solitons in conducting polymers. Acc. Chem. Res. 1985, 18 (10), 309-315.

51. https://en.m.wikipedia.org/wiki/Log-normal distribution\#. $27^{\text {th }}$ July 2021

52. Kirkpatrick, S., Classical Transport in Disordered Media: Scaling and Effective-Medium Theories. Phys. Rev. Lett. 1971, 27 (25), 1722-1725.

53. Kirkpatrick, S., Percolation and Conduction. Rev. Mod. Phys. 1973, 45 (4), 574-588.

54. Chabanis, G.; Parkin, I. P.; Williams, D. E., A simple equivalent circuit model to represent microstructure effects on the response of semiconducting oxide-based gas sensors. Meas Sci Technol. 2002, 14 (1), 76-86.

55. Wang, S. C.; Chang, K. S.; Yuan, C. J., Enhancement of electrochemical properties of screenprinted carbon electrodes by oxygen plasma treatment. Electrochim. Acta. 2009, 54 (21), 4937-4943.

56. Osbome, M.; Seddon, B.; Dryfe, R.; Lagger, G.; Loyall, U.; Schäfer, H.; Girault, H. J. J. o. E. C., Excimer laser-induced electrochemical activity in carbon ink films. J. Electroanal. Chem. 1996, 417 (12), 5-15.

57. Fanjul-Bolado, P.; Hernández-Santos, D.; Lamas-Ardisana, P. J.; Martín-Pernía, A.; Costa-García, A., Electrochemical characterization of screen-printed and conventional carbon paste electrodes. Electrochim. Acta. 2008, 53 (10), 3635-3642.

58. Xu, G.; Jarjes, Z. A.; Wang, H.-W.; Phillips, A. R. J.; Kilmartin, P. A.; Travas-Sejdic, J., Detection of Neurotransmitters by Three-Dimensional Laser-Scribed Graphene Grass Electrodes. ACS Appl. Mater. Interfaces. 2018, 10 (49), 42136-42145. 
59. Xu, G.; Jarjes, Z. A.; Desprez, V.; Kilmartin, P. A.; Travas-Sejdic, J., Sensitive, selective, disposable electrochemical dopamine sensor based on PEDOT-modified laser scribed graphene. Biosens. Bioelectron. 2018, 107, 184-191.

60. Chan, E. W. C.; Baek, P.; Tan, S. M.; Davidson, S. J.; Barker, D.; Travas-Sejdic, J., Molecular "Building Block" and "Side Chain Engineering": Approach to Synthesis of Multifunctional and Soluble Poly(pyrrole phenylene)s. Macromol. Rapid Commun. 2019, 40 (10), 1800749.

61. Fan, X.; Lin, L.; Messersmith, P. B., Cell Fouling Resistance of Polymer Brushes Grafted from Ti Substrates by Surface-Initiated Polymerization: Effect of Ethylene Glycol Side Chain Length. Biomacromolecules. 2006, 7 (8), 2443-2448.

62. Zhu, B.; Booth, M. A.; Shepherd, P.; Sheppard, A.; Travas-Sejdic, J., Distinguishing cytosine methylation using electrochemical, label-free detection of DNA hybridization and ds-targets. Biosens. Bioelectron. 2015, 64, 74-80.

63. Khadka, R.; Aydemir, N.; Carraher, C.; Hamiaux, C.; Colbert, D.; Cheema, J.; Malmström, J.; Kralicek, A.; Travas-Sejdic, J., An ultrasensitive electrochemical impedance-based biosensor using insect odorant receptors to detect odorants. Biosens. Bioelectron. 2019, 126, 207-213.

64. Williams, D. E.; Pratt, K. F. E., Microstructure effects on the response of gas-sensitive resistors based on semiconducting oxides. Sens. Actuators B Chem. 2000, 70 (1), 214-221. 